\title{
Social exclusion in old age: domain-specific contributions to a debate
}

\author{
BY SANDRA TORRES*
}

\section{Introduction}

Finding a suitable way to write an introduction to a Special Issue would seem to be a relatively easy task - at first glance. But when the Special Issue is dealing with a notion that is in the very midst of receiving momentum, the question arises of how one should begin, because although some potential readers may be acquainted with the topic at hand, others may have yet to understand that the topic is now in the process of conquering intellectual space. This Special Issue happens to be about such a topic. The topic of social exclusion in old age does not yet seem to be on the radar of North American scholars, for example, but has certainly become a topic to reckon with in Europe. Understanding how "the notion of social exclusion has found its way into the lexicon of all major global governance institutions" (O'Brien \& Penna 2008: 1) is what this introduction is all about. This Special Issue was, after all, first conceived as part of the series of special issues that the COST-action known as ROSENet (an acronym that stands for Reducing Old Age Social Exclusion: Collaborations in Research and Policy; www.rosenet.com) would put together to raise awareness about old-age social exclusion - a phenomenon that deserves attention as populations around the world grow older and live longer. 
International Journal of Ageing and Later Life

For those who are not familiar with what COST-actions are, COST stands for European Collaborations in Science and Technology and is an organization that offers, among other things, European funding to facilitate the establishment of research networks that can address an issue deemed to be of concern not only for scholars but also for policymakers. The actual COST-funded network behind this Special Issue (i.e. ROSENet) brings together over 140 researchers (from 30+ countries) who have been working together - through an array of activities - on the dimensions of old-age social exclusion that have been identified (i.e. economic, social relations, services, community/spatial, civic and symbolic) ever since social exclusion entered the vernacular of European politics about three decades ago. To this end, it would seem to be important to mention that - although it took time before the notion of social exclusion "conquered" discourses about poverty and disadvantage, and although we have seen how the opposite term of social inclusion has slowly come to be widely used by policymakers (Jehoel-Gijsbers \& Vrooman 2008) - it has become increasingly clear that social exclusion has made its entrance into the social scientific debate on inequalities, in general, and the gerontological version of inequality, in particular. Both of these facts will be addressed in the sections that follow. For now, all I wish to draw attention to is that, at this juncture, research on how old-age social exclusion can be measured is needed as well as on the specific domains associated with it.

This Special Issue deals with the domains concerned with exclusion from social relations, services, community/spatial exclusion and civic participation. A few words about the broader picture would seem to be necessary, however, if we are to understand why so many social gerontologists in Europe are focusing their attention on this topic. And the first thing to say in this respect is that in one of the first measurements of social exclusion levels among the EU countries (using the first four waves of the European Community Household Panel [ECHP]; i.e. 1994-1997) which did not focus on old-age social exclusion per se, but does seem to have played a role in igniting the gerontological debate on this issue - it was clearly stated that although social exclusion does not appear to be a problem everywhere in Europe, being an older citizen living alone or a member of an elderly couple was positively associated with the risk of social exclusion in Southern Europe (Tsakloglou \& Papadopoulos 2002). 
A few years later, Ogg (2005) published a paper using data from the first round of the European Social Survey and looking specifically at old-age social exclusion. He found similar results, that is, the link between developed welfare regimes and low rates of social exclusion in later life was confirmed [see also Jehoel-Gijsbers \& Vrooman 2008 for similar results based on combined data from three surveys: European Social Survey (ESS 2002); European Union Statistics on Income and Living Conditions (EU-SILC 2005) and The Survey of Health, Ageing and Retirement in Europe (SHARE 2004)]. In a more recent study using a large dataset from Sweden, one of the countries where risks for old-age social exclusion are believed to be comparatively low, Heap et al. (2012) not only found that the $75+$ population exhibits the highest odds of coexisting disadvantages but also that the variation within the group we often designate as advanced old age (i.e. $85+$ ) is far greater than most seem to understand. Based on data collected through the English Longitudinal Study of Aging, Steptoe et al. (2013) noted that the inequalities in later life are evident not only because "the wealth distribution is heavily skewed" (Steptoe et al. 2013: 1645) but also because this inequality extends to the cultural, social and civic, and health realms. It is research results such as these that have led European social gerontologists to regard old-age social exclusion as a topic in need of scholarly attention.

\section{Social Exclusion: The Policy Phrase and the Scientific Term}

The fact that the topic at hand has gained such momentum may seem puzzling to some, considering that the notion of social exclusion has been contested from the start (e.g. Levitas 1996, 1998; Silver 1994, 2007). One of the most utilized definitions of this term, however, is offered by Levitas et al. (2007), who defined social exclusion as follows:

A complex and multi-dimensional process. It involves the lack or denial of resources, rights, goods and services, and the inability to participate in the normal relationships and activities, available to the majority of people in a society, whether in economic, social, cultural or political arenas. It affects both the quality of life of individuals and the equity and cohesion of society as a whole. (p. 9)

Saunders (2008) argued that this term has been disputed from the start owing to "its flexibility," and that it is this very suppleness that has 
International Journal of Ageing and Later Life

"allowed researchers and policy makers to engage in a productive dialogue that draws together otherwise disparate themes, with the promise of developing practical solutions to policy problems. The policy interest has thus acted as a spur to researchers, and their interest and contributions have enriched the policy dialogue" (Saunders 2008: 80).

Peace (2001) - who wrote a dissertation on the discursive shifts European Union policies on poverty made between the mid-1970s and late 1990s - argued that the phrase "social exclusion" was virtually nonexistent in policy documents in English from the 1970s. It appeared, however, in the 1980s through European Union (EU) policy initiatives on poverty, because, he claimed, there was a need to coin a policy phrase to replace the stigmatizing term used at the time, which was poverty. The fact that social exclusion was a recognizable phrase in the French-speaking part of the EU made adopting it in European policy circles relatively easy. To this end, it is important to note that the notion of "exclusion sociale" was already a part of France's political debate at that time (see Béland 2007 for insight into how the notion and discourse on social exclusion as a basis for policy change was originally used in that context). Peace (2001) claimed therefore that because the mandatory languages for all European Union policy documents were English and French at the time, it made perfect sense to adopt the policy phrase "social exclusion" when initiatives to combat marginalization and depravation were being discussed.

Peace (2001) also claimed that the discursive turn that European poverty policy took at that time - from poverty to social exclusion - could be regarded as a branding exercise for the controversial poverty initiatives being launched by the European Union. Explaining the exact reasons why these initiatives were deemed divisive is beyond the scope of the present article (see, however, Béland 2007 who compares the British and the French discourse on social exclusion and shows differences in how these initiatives can be regarded depending on the country in which they have been launched; see also Bradshaw 2004). Suffice it to say that the policy phrase lurking in the background of this Special Issue - a phrase European social gerontologists like myself have appropriated (and are debating) through an initiative of our own: the COST-action ROSENet is a phrase that has received considerable attention over the past three decades. 
Although it is often acknowledged that drawing a line between social exclusion, inequality, marginalization, disadvantage, and the more easily identifiable chronic poverty is not an easy task, the pull that the policy phrase has is undeniable. To some extent, it makes perfect sense that the launching of this phrase into the European policy vernacular paved the way for the scientific debate on social exclusion that had been ongoing since the late 1980s. The fact that social gerontologists have appropriated this term over the past decade also makes perfect sense, considering what was mentioned in the introduction of the present article. There are, however, many definitions for this term, depending, of course, on the research field in which it is used (see, e.g. the definitions offered by Silver 1994 and Abrams et al. 2007, to name a few). In other words, there is no consensus among scholars as to how social exclusion should be defined and/or measured. But the bigger strokes of what this notion is all about are seldom disputed, so it is those bigger strokes I bring attention to in this introduction to a Special Issue on old-age social exclusion.

A few words about definitions are in order. Silver (2007) - who offered a fairly comprehensive discussion of the difference between social exclusion and chronic poverty over a decade ago - defined social exclusion as the "dynamic process of progressive multidimensional rupturing of the 'social bond' at the individual and collective levels" (p. 1). Her definition stresses the bonds between individuals and the societies they inhabit and, as such, offers a more comprehensive and complex conceptualization of social disadvantage than chronic poverty does. Thus, although the policy phrase social exclusion was originally used to launch controversial EU policy initiatives that were primarily concerned with the lack of material resources that some people experienced, the scientific term (and the various debates that it has ignited) brings together the economic dimensions of disadvantage and the relational aspects in a way the debate on poverty never did (Bhalla \& Lapeyre 1997). To this end, it would seem appropriate to mention an observation made by a social policy scholar who was originally skeptical of the fact that the "French concept of exclusion sociale (had) crossed the channel" (Bradshaw 2004: 170), and could not see what the new term had to offer. In an article he wrote to "justify (his) change of heart" (Bradshaw 2004: 171), he argued that owing to the interesting ways in which social scientists have begun to operationalize social exclusion, 
International Journal of Ageing and Later Life

we have been able to grasp that "the poor are more likely to be socially excluded and the poorer you are the more socially excluded you are likely to be, but not on all dimensions. The existence of valuable social relationships - social capital - does not seem to be particularly related to poverty, possibly because the poor have more time to maintain them" (Bradshaw 2004: 184).

Irrespective of whether one regards social exclusion primarily as a question of the outcome of a lack of material resources or as the structural processes underlying social isolation, the interesting thing about the scientific term social exclusion is that it draws attention to the array of activities, relationships, and resources that are needed for people to experience adequate social participation and a certain degree of power over their situation (Room 1995). Saunders (2008) argued that "it was the limitations of the concept of poverty rather than its measurement problems that led to the emergence of social exclusion as an alternative paradigm in Europe" (p. 75). He further claimed (as others have also done) that it was the problematic and mistaken homogenization of "the poor," "characterized by a single common factor, low-income (relative to need)" (Saunders 2008), that led to the demise of poverty as a policy priority. Irrespective of what one thinks about the "replacement" of poverty with social exclusion, and the array of policy initiatives and discourses that this replacement ignited, it is important to note that the verdict on definitions and measurements of social exclusion is not yet out. The same can be said for the debates on whether or not the distinction between poverty and social exclusion is a fruitful one, and on what constitute fruitful indicators of social exclusion (Halleröd \& Larsson 2008; see also Room 1995 for insight into how the evolution of European anti-poverty programs shifted the language of disadvantage).

Berghman's (1997) definition of social exclusion - as the non-realization of citizenship rights - is, however, an appropriate one to bring to the fore here, as it is one of the first to list the arenas from which a person or group can be excluded. Early on, he identified the spheres of normal relationships and activities that are important to the realization of citizenship rights by referring to the societal systems where inclusion takes place:

- the democratic and legal system (which make civic integration possible) 
- the labor market (which makes economic integration possible)

- the welfare system (which is key to social integration)

- the systems of social networks of affiliation (which make interpersonal integration possible)

Burchardt et al. (1999) focused, in turn, on the activities we all need to engage in if we are to combat social exclusion (see also Hills et al. 2002). These are:

- production activities (which in their model pertain not only to economically valued activities but also to socially valued ones)

- consumption activities (which refer to individuals' ability to consume the types of goods and services considered "normal" in a society)

- savings activities (which refer to the accumulation of savings, pension entitlements or property ownership)

- political activities (which concern the types of collective efforts people make to improve their immediate or wider environment)

- social activities (which entail engagement in significant social interaction through one's networks of affiliations as well as identification with a cultural group or community).

The array of spheres and/or activities that have been listed when the scientific term "social exclusion" has been debated is large, but on close inspection it is primarily the activities and spheres listed above that are mentioned. Worth noting is also the fact that scholars have differing views on the role that they believe the welfare state can play in combating social exclusion. For example, O’Brien and Penna (2008) argued:

...there is at least a prima facie case for seeing "integrative" institutions of Europe as locked into processes of discrimination and marginalization. When questions of gender, race, class and colonialism are applied to the institutions of the political and economic subsystems, it becomes clear that these institutions are infused with cultural and historical identities, statuses and expectations. Exclusion, it can be argued, is not a by-product of system malfunction, it is woven into the fabric of those institutions - the labor market and the welfare state - that are offered as the means to resolve the problem of exclusion. (O'Brien \& Penna 2008: 89, see also O'Brien \& Penna 1996) 
International Journal of Ageing and Later Life

Thus, although the policy term "social exclusion" was used to launch European initiatives to combat the types of "marginalization" that poverty can lead to - marginalization that encompasses an array of societal spheres - there are social scientists who do not believe that policymakers' efforts can succeed in eliminating social exclusion. Most social gerontologists who depart from the holy trinity of research, policy and practice seem to think that policies to combat social exclusion can have an impact on the way in which cumulative disadvantage over the life course is addressed (see Dannefer 2003 and Ferraro \& Shippee 2009 for insights into the gerontological debate on cumulative disadvantage), and that collaborations between scholars, policymakers, and practitioners working with and for older people are key to managing the formulation and implementation of such policies. The COST-action initiative ROSENet is an example of a scholar-driven initiative that aims to contribute not only to the scholarly debate on old-age social exclusion but also to the formulation and implementation of policies and practices that can address the types of social exclusion some older people are at risk of experiencing.

\section{Social Exclusion in Old Age: The Gerontological Debate}

Pinpointing exactly when the gerontological debate on social exclusion started is not an easy task. The early 2000s, however, would seem to be the period in which a number of articles debating the fruitfulness of the concept of social exclusion for studies of aging and old age began to surface (van Regenmortel et al. 2016). This abridged section offers a chronological presentation of some of the most cited contributions to the gerontological debate on social exclusion. The chronology hereby presented is in no way comprehensive, as it only includes publications that have explicitly used the term social exclusion and old age (or other euphemisms for this part of the life course) in their titles. Having said this, it is perhaps necessary to state that the reason I have chosen to rely on chronology here is that it is easier to tease out how the gerontological discussion has developed when one looks at the literature in this manner.

From the start, the gerontological "appropriation" of the social scientific debate on social exclusion was conditioned, because the need to "adapt" the notion for use as a theoretical lens through which to study 
old-age-related disadvantages was a given (Scharf et al. 2001). The reason for this was rooted in the fact that the heavily criticized notion of "paid work as a major factor in social integration" (Levitas 1998: 27) was so central to the original discussion, and during old age engagement in paid work is not a given. Relatively early on in the process hereby described, empirical evidence from a study on older people living in some of England's most deprived neighborhoods was used to propose how the notion of social exclusion could be "adapted" for gerontological use (i.e. Scharf et al. 2005). The reason such neighborhoods received attention to begin with is probably that, very early on in the debate on social exclusion, it was stated that one of the attributes of this notion was that "this deprivation has a neighborhood dimension, since it can be caused not only by lack of personal resources but also by insufficient or unsatisfactory community resources" (Tsakloglou \& Papadopoulos 2002: 212). Thus, by arguing that social exclusion draws attention to the social costs that disengagement from society can entail, Scharf et al. (2005) proposed that the study of disadvantage in old age could benefit from a deeper understanding of the debate on social exclusion.

Worth noting is also the fact that the process of appropriating and adapting the notion of social exclusion for usage in the social gerontological vernacular (which is ongoing) entailed - from the start - identification of the activities we ought to regard as crucial to old age inclusion. For example, Scharf et al. (2005) argued that at least five types of social exclusion were relevant to older people (i.e. material resources, social relations, civic activities, basic services and neighborhood). The resemblance to the dimensions mentioned in the previous section is striking, as are the differences, as neither the service nor the spatial dimension was among the dimensions mentioned earlier. By stating this, I am not claiming that it was social gerontologists who put those dimensions on the social exclusion map, so to speak, but rather that the distinctiveness of old age was at the forefront of the gerontological discussion on old-age social exclusion at an early stage.

In the same year that the abovementioned scholars continued to set in motion the gerontological discussion on social exclusion, a paper was published in a policy journal that drew attention to the role that place plays in the lives of older people existing on the margins (Abbott \& 
International Journal of Ageing and Later Life

Sapsford 2005). Also that same year, Ogg (2005) used data from the European Social Survey to analyze the prevalence of social exclusion among older people in the three types of welfare regimes often alluded to in this part of the world (i.e. the Nordic, Mediterranean and the Post-socialist regimes). The results showed that there is a link between developed welfare regimes and low rates of old-age social exclusion. Although these results were in no way revolutionary, Ogg's article seems to be one of the first peer-reviewed contributions to the gerontological debate that applied social exclusion indicators (in this case 11 indicators were used, among others: income, social isolation, social activities, political engagement, well-being, and self-rated health) to the study of older people's situation in an array of spheres.

A few years later, Cavalli et al. (2007) studied how three critical life events (i.e. deterioration of health, death of a close relative, entry into a nursing home) impact the oldest old's relational life and social involvement. Just a year after, Moffatt and Scambler (2008) studied whether welfare rights advice could combat social exclusion in old age, while Grenier and Guberman (2009) utilized a Canadian framework to study social exclusion - a framework that relies on seven types of exclusion (symbolic, identity, sociopolitical, institutional, economic, meaningful relations and territorial exclusion) to argue that older people who cannot afford to supplement public care with private services risk social exclusion. Moffatt and Glasgow (2009) also published a contribution to the debate around the same time, asking whether the concept of social exclusion is useful in studying the situation of rural older people in both the United Kingdom and the United States. Just like Grenier and Guberman (2009), these social gerontologists noted that the North American gerontological debate had yet to engage with the concept of social exclusion and that much could be gained if the "the institutional entrenchment of the poverty discourse in the US" (Moffatt \& Glasgow 2009: 1301) were to be replaced by the more dynamic notion of social exclusion, at least with regard to disadvantaged older people living in rural areas. A few years later, O'Shea et al. (2012) tapped into how Irish older people, here too living in rural areas, conceptualized the relationship between age and social exclusion. Their findings proposed that four interconnected thematic areas were important to how older people living in rural areas regard social exclusion (these were: place, economic circumstances, social provision, and social 
connectedness). Both of these last-mentioned papers - together with the articles published by Scharf and colleagues mentioned earlier - argued that it matters where old age exclusion is experienced, and showcased the fact that, from the very start, the situation of rural older people and/or of those who live in disadvantaged neighborhoods has been at the forefront of the gerontological debate on social exclusion.

During the past few years, we have witnessed a steady increase in the number of publications dedicated to social exclusion in old age. These publications have slowly but surely extended the angles of investigation used. Scharf and Keating published, for example, an edited collection in 2012 arguing that social exclusion in later life was becoming a global challenge not only because population aging demands our attention but also because many Western nations are experiencing both austerity and growing economic instability, and these phenomena have brought with them individualization of the risks associated with aging. In this edited collection, an array of social gerontologists (myself included) have tackled the question of old-age social exclusion from different perspectives (some did so from the perspective that a material, social, spatial, and symbolic focus offers, while others did so from the perspectives that globalization and international migration offer). A year later, social gerontologists based in Central and Eastern Europe added their two cents to the debate by using data from the European Quality of Life Survey to study social exclusion among older people in that part of the world. They argued that their findings - which showed that older people in these countries were experiencing greater social exclusion than both older people in other European countries and their younger counterparts in Central and Eastern European countries revealed that "post-socialists welfare states do not promote inclusion of the elderly in a satisfactory degree" (Hrast et al. 2013: 971).

A year later, the topic of social exclusion in relation to rural older people was on the agenda again when Walsh et al. (2014) assessed the relevance of the "age-friendly" concept for this population by shedding light on the informal practices these older people use to address social exclusion. A few years later, a systematic (van Regenmortel et al. 2016) and a scoping review (Walsh et al. 2017) were published on old-age social exclusion. The systematic review included only the 26 articles that explicitly focused on social exclusion/ inclusion in later life. This review showed not only how the debate had evolved but also how old-age social exclusion had been conceptualized 
International Journal of Ageing and Later Life

thus far. One of the noteworthy things mentioned in this review was that the life course approached is "little applied in studies addressing social exclusion or inclusion in later life" (van Regenmortel et al. 2016).

The scoping review by Walsh et al. (2017) approached the topic from a broader perspective by mapping out what the research to date on later life has suggested about social exclusion. Acknowledging that "the full body of literature pertaining to old age social exclusion may be conceptual and empirical; scattered across different literatures; specific to only one exclusion domain (e.g. financial and material resources); and may not even be labelled or referred to as exclusion" (Walsh et al. 2017: 83), these social gerontologists conducted a two-stage review of the available literature (which included $440+$ sources). The research questions guiding their endeavor were twofold: first, they wanted to shed light on how old-age social exclusion has been conceptualized thus far; second, they wanted to shed light on the main themes that the literature touches upon in relation to the domains of old-age social exclusion that the first stage of their review had identified (i.e. neighborhood and community; services; amenities and mobility; social relations; material and financial resources; sociocultural aspects, and civic participation). Worth noting - considering that this Special Issue is one of the ones that the COST-action ROSENet (Reducing Old Age Social Exclusion) has brought together - is that it is on the basis of these domains that this network has been working since it was first established. Of particular relevance to this Special Issue is the definition Walsh et al. (2017) offered in their scoping review:

Old-age exclusion involves interchanges between multi-level risk factors, processes and outcomes. Varying in form and degree across the older adult life course, its complexity, impact and prevalence are amplified by old-age vulnerabilities, accumulated disadvantage for some groups, and constrained opportunities to ameliorate exclusion. Old-age exclusion leads to inequities in choice and control, resources and relationships, and power and rights in key domains of neighborhood and community; services, amenities and mobility; material and financial resources; social relations, socio-cultural aspects of society; and civic participation. Old-age exclusion implicates states, societies, communities and individuals. (p. 93)

This definition brings attention to the multilevel factors, processes, and outcomes associated with old-age exclusion, whose impacts are amplified 
by the array of vulnerabilities with which old age is associated. In recent years, a few more articles on old-age social exclusion have been published. Some of these articles are based on the work that the Economic and Social Research Council (ESRC) Centre for Analysis of Social Exclusion (CASE) is generating. Sacker et al. (2017), for example, has used the UK Household Longitudinal Study to study how older people's health is related to social exclusion. Macleod et al. (2019), in turn, proposed a framework for measuring social exclusion in later life, which they argued offers us "a platform that will enable research to move beyond descriptive analysis to a more detailed examination of the relationships between different dimensions of exclusion and possible mediating and moderating factors" (p. 78). In this framework, they started from the domains spelled out by Walsh et al. (2017), but considered health and well-being to be a domain of its own. The testing of this framework - which used data from the first three waves of the UK longitudinal study hereby mentioned showed that "as expected, the degree of exclusion experienced by people increased with age, with the oldest old experiencing more exclusion overall and on each domain" (Macleod et al. 2019: 101).

The work reviewed in this section has hopefully given an adequate insight into how the debate on old-age social exclusion has evolved (from an interest in the ways in which community/spatial exclusion impacts old age to the manner in which social exclusion in old age can be measured in a comprehensive enough fashion). The number of angles of investigation that deserve our attention is large at this juncture, as the research on oldage social exclusion is still in its infancy. It is, however, clear that the vulnerabilities associated with advanced old age are at the very core of the debate thus far. It is our growing concern with what these vulnerabilities may mean for quality of life in old age that is the driving force behind European social gerontologists' increasing interest in this notion.

\section{This Special Issues' Contributions to the Ongoing Debate}

This Special Issue - which is entitled Old-age exclusion: theoretical, conceptual and critical policy contributions - aims to make four dimension-specific contributions to the ongoing discussion on old-age social exclusion. In keeping with the title of the issue, we have an article by Wanka and 
International Journal of Ageing and Later Life

colleagues that makes a theoretical/conceptual contribution by focusing on the domain of old-age social exclusion known as neighborhood and community. Their article - which aims to broaden what the authors refer to as the Anglo-Saxon hegemony of the gerontological literature on socio-spatial environments - introduces concepts from urban and environmental sociology in order to expand the gerontological vernacular on socio-spatial exclusion and bring to the fore new questions that are not yet part of present-day discussions on the dimension of old-age social exclusion that Walsh et al. (2017) called "neighborhood and community."

The second article in this Special Issue is by Serrat and colleagues. This paper makes an empirical contribution to the discussion on old-age social exclusion that deals specifically with the domain of civic exclusion. Looking into the barriers to political participation that older people who are active in senior organizations in Spain and Australia experience (and have given voice to through two different projects), their article could be said to add to the critical policy perspective that this Special Issue is hoping to contribute to, as the empirical evidence offered in this piece can be used to facilitate participation in these organizations - something that policymakers deem to be necessary if active aging is to take place.

De Tavernier and Draulans have written the third article in this Special Issue and tackle the domain alluded to as services, amenities, and mobility in Walsh et al.'s (2017) scoping review. In their paper, it is the informal care arrangements of the Turkish immigrant community in Belgium that are brought to the fore through stakeholder interviews. Using an array of theoretical frameworks to explain how informal care plays out, their article alludes to the ways in which social exclusion in old age affects the care negotiations that take place between older migrants and their families.

The fourth and final contribution to this Special Issue comes in the form of an article by Winter and Burholt, who bring attention to the rural angle that ignited (as shown in the previous section) much of the debate on old-age social exclusion. In this contribution, they use a critical human ecological framework to make sense of the cultural exclusion that a rural-dwelling group of older adults in South Wales experience.

Taken as a whole, we hope this collection of articles will contribute to the debate on old-age social exclusion by offering new insights into domain-specific questions. In doing so, these articles bring to fore the 
complexities that using a social exclusion lens can expose, and they urge us (albeit in indirect ways) to continue thinking about what this lens offers to the study of aging and old age.

\section{References}

Abbott, P. \& Sapsford, R. (2005). Living on the margins: Older people, place and social exclusion. Policy Studies 26(1): 29-46.

Abrams, D., Christian, J. \& Gordon, D. (eds) (2007). Multidisciplinary Handbook of Social Exclusion Research. Hoboken: Wiley.

Bhalla, A. \& Lapeyre, F. (1997). Social exclusion: Towards an analytical and operational framework. Development and Change 28(3): 413-433.

Béland, D. (2007). The social exclusion discourse: Ideas and policy change. Policy \& Politics 35(1): 123-139.

Berghman, J. (1997). The resurgence of poverty and the struggle against exclusion: A new challenge for social security. International Social Security Review 50(1): 3-21.

Bradshaw, J. (2004). How has the notion of social exclusion developed in the European discourse? The Economic and Labour Relations Review 14(2): 168-189.

Burchardt, T., Le Grand, J. \& Piachaud, D. (1999). Social exclusion in Britain 1991-1995. Social Policy and Administration 33(3): 227-244.

Cavalli, S., Bickel, J.-F. \& Lalive D’Epinay, C. J. (2007). Exclusion in very old age: The impact of three critical life events. International Journal of Ageing and Later Life 2(1): 9-31.

Dannefer, D. (2003). Cumulative advantage/disadvantage and the life course: Cross-fertilizing age and social science theory. Journal of Gerontology: Social Sciences 58: S327-S337.

Ferraro, K. F. \& Shippee, T. P. (2009). Aging and cumulative inequality: How does inequality get under the skin? The Gerontologist 49(3): 333-343.

Grenier, A. \& Guberman, N. (2009). Creating and sustaining disadvantage: The relevance of the social exclusion framework. Health and Social Care in the Community 17(2): 116-124.

Halleröd, B. \& Larsson, D. (2008). Poverty, welfare problems and social exclusion. International Journal of Social Welfare 17: 15-25. 
International Journal of Ageing and Later Life

Heap, J., Lennartsson, C. \& Thorslund, M. (2012). Coexisting disadvantages across the adult age span: A comparison of older and younger age groups in the Swedish welfare state. International Journal of Social Welfare 22: 130-140.

Hills, J., Le Grand, J. \& Piachaud, D. (eds.) (2002). Understanding Social Exclusion. Oxford: Oxford University Press.

Hrast, M. F., Mrak, A. K. \& Rakar, T. (2013). Social exclusion of elderly in Central and Eastern Europe. International Journal of Social Economics 40(11): 971-989.

Jehoel-Gijsbers, G \& Vrooman, C. (2008). Social Exclusion of the Elderly: A Comparative Study of EU Member States. European Network of Economic Policy Research Institute (ENEPRI) Research Report no. 57.

Levitas, R. (1996). The concept of social exclusion and the new Durkheimian hegemony. Critical Social Policy 16(46): 5-20.

Levitas, R. (1998). The Inclusive Society: Social Exclusion and New Labour. Basingstoke: Macmillian.

Levitas, R., Pantazis, C., Fahmy, E., Gordon, D., Lloyd, E. \& Patsios, D. (2007). The Multi-dimensional Analysis of Social Exclusion. Bristol: Department of Sociology and School for Social Policy, Townsend Center for the International Study of Poverty and Bristol Institute for Public Affairs, University of Bristol.

Macleod, C. A., Ross, A., Sacker, A., Netuveli, G. \& Windle, G. (2019). Rethinking social exclusion in later life: A case for a new framework for measurement. Ageing \& Society 39: 74-111.

Moffatt, S. \& Glasgow, N. (2009). How useful is the concept of social exclusion when applied to rural older people in the United Kingdom and the United States. Regional Studies 43(10): 1291-1303.

Moffatt, S. \& Scambler, G. (2008). Can welfare-rights advice targeted at older people reduce social exclusion? Ageing \& Society 28(6): 875-899.

O'Brien, M. \& Penna, S. (1996). Postmodern theory and politics: Perspectives on citizenship and social justice. Innovation: The European Journal of Social Science 9: 185-203.

O'Brien, M. \& Penna, S. (2008). Social exclusion in Europe: Some conceptual issues. International Journal of Social Welfare 17(1): 84-92.

Ogg, J. (2005). Social exclusion and insecurity among older Europeans: The influence of welfare regimes. Ageing \& Society 25: 69-90. 
O'Shea, E., Walsh, K. \& Scharf, T. (2012). Exploring community perceptions of the relationship between age and social exclusion in rural areas. Quality in Aging and Older Adults 13(1): 16-26.

Peace, R. (2001). Social exclusion: A concept in need of definition? Social Policy Journal of New Zealand 16: 17-36.

Room, G. (ed.) (1995). Beyond the Threshold: The Measurement and Analysis of Social Exclusion. Bristol: Policy Press.

Sacker, A., Ross, A., Macleod, C. A., Netuveli, G. \& Windle, G. (2017). Health and social exclusion in older age: Evidence from the understanding society, the UK household longitudinal study. Journal of Epidemiology \& Community Health 71(7): 681-690.

Saunders, P. (2008). Social exclusion: Challenges for research and implications for policy. The Economic and Labour Relations Review 19(1): 73-92.

Scharf, T. \& Keating, N. C. (eds) (2012). From Exclusion to Inclusion in Old Age: A Global Challenge. Bristol: Policy Press.

Scharf, T., Phillipson, C., Kingston, P. \& Smith, A. E. (2001). Social exclusion and older people: Exploring the connections. Education and Aging 16(3): 303-319.

Scharf, T., Phillipson, C. \& Smith, A. E. (2005). Social exclusion of older people in deprived urban communities of England. European Journal of Ageing 2(2): 76-87.

Silver, H. (1994). Social exclusion and social solidarity: Three paradigms. International Labour Review 133: 531-578.

Silver, H. (2007). The Process of Social Exclusion: The Dynamics of an Evolving Concept. Working paper 95. Chronic Poverty Research Centre (CPRC). Rhode Island, USA: Department of Sociology, Brown University.

Steptoe, A., Breeze, E., Banks, J. \& Nazroo, J. (2013). Cohort profile: The English Longitudinal Study of Aging. International Journal of Epidemiology 42: 1640-1648.

Tsakloglou, P. \& Papadopoulos, F. (2002). Aggregate level and determining factors of social exclusion in twelve European countries. Journal of European Social Policy 12(3): 211-225.

van Regenmortel, S., de Donder, L., Dury, S., Smetcoren, A.-S., de Witte, N. \& Verté, D. (2016). Social exclusion in later life: A systematic review of the literature. Population Aging 9: 315-344. 
International Journal of Ageing and Later Life

Walsh, K., O'Shea, E., Scharf, T. \& Shucksmith, M. (2014). Exploring the impact of informal practices on social exclusion and age-friendliness for older people in rural communities. Journal of Community \& Applied Social Psychology 24: 37-49.

Walsh, K., Scharf, T. \& Keating, N. (2017). Social exclusion of older persons: A scoping review and conceptual framework. European Journal of Ageing 14: 81-98. 